\title{
JOGLO ARCHITECTURE DEVELOPMENT FOR POST EARTHQUAKE TEMPORARY SHELTER
}

\author{
${ }^{1}$ Theodorus Alvin. ${ }^{2}$ Yenny Gunawan, S.T., M.A. \\ ${ }^{1}$ Student in the Bachelor's (S-1) Study Program in Architecture \\ at Parahyangan Catholic University \\ 2 Senior lecturer in the Bachelor's (S-1) Study Program in Architecture \\ at Parahyangan Catholic University
}

\begin{abstract}
Java Island is one of many islands which has a lot of active volcanoes and also intersected by many active tectonic plates, which cause the locals of the island to be vulnerable and exposed to natural disaster. High population in the island causes the evacuation and post-disaster handling become difficult. One solution to answer the needs of livable housings is temporary shelter. But, many temporary shelters are designed and developed with too many modern features, which caused the shelters to be expensive and hard to be built with participatory methods. Therefore, the idea to adapt Joglo architecture capability of knock-down system as temporary shelter is developed. The research aims to: (1) know the strength and weakness of Joglo architecture as post-earthquake temporary shelter; and (2) develop design prototypes of temporary shelters which adapt Joglo architecture

The methods used in this research is experimental research, which focused on designs that adapt the ability of knock-down in Joglo architecture and later applied in temporary shelters. The data used to support the research are design guidelines and criteria of temporary shelters stated by UNHCR (2011) and the functionality and technical aspects of Joglo architecture composed by Frick (1997). After analyzing the data of Joglo architecture, then the result will be analyzed again with the design criteria of temporary shelters in effectivity and efficiency aspects. The next phase is stating the strengths and weaknesses of Joglo architecture as temporary shelter.

These strengths will be developed, meanwhile the weakness will be handled without diminishing the existing potentials of Joglo architecture as temporary shelter. The final phase is developing 2 types of temporary shelters design prototypes, which have alternatives based on the construction material; coconut wood (type I) and wulung bamboo (type II). These materials are used in order to replace the authentic material of Joglo, teak wood, which is not efficient as temporary shelters structural material. These 2 types of temporary shelters are able to fulfil the design criteria of temporary shelter, because these prototypes are functional (effective) and able to fulfil technical requirements (efficient). Along with this research, the writer hoped that in the future there will be many traditional architectures which will be adapted as a solution to respond the issue of post-disaster architecture.
\end{abstract}

Key Words: Joglo, knock-down, temporary shelter, post-earthquake

\section{PENGEMBANGAN ARSITEKTUR JOGLO UNTUK TEMPORARY SHELTER PASCAGEMPA}

\author{
${ }^{1}$ Theodorus Alvin. ${ }^{2}$ Yenny Gunawan, S.T., M.A. \\ ${ }^{1}$ Mahasiswi S1 Program Studi Arsitektur Universitas Katolik Parahyangan \\ ${ }^{2}$ Dosen Pembimbing S1 Program Studi Arsitektur Universitas Katolik Parahyangan
}

\begin{abstract}
Abstrak- Pulau Jawa merupakan salah satu pulau dengan jumlah gunung berapi terbanyak, dilalui berbagai lempeng tektonik aktif, menyebabkan pulau ini sangat rawan terhadap bencana gempa. Jumlah populasi penduduk yang tinggi di Pulau Jawa, menyebabkan proses penanganan korban pascagempa menjadi sulit. Salah satu solusi dalam menjawab kebutuhan korban akan kebutuhan akan hunian yang layak, praktis dan murah adalah temporary shelter. Namun, kebanyakan temporary shelter dirancang secara modern, sehingga masih tergolong sulit, mahal
\end{abstract}

\footnotetext{
${ }^{1}$ Corresponding Author: theodorusalvin120@gmail.com
} 
dan tidak lazim untuk dibangun oleh masyarakat secara partisipatori dalam kondisi pascagempa. Maka dari itu, muncul gagasan untuk mengadaptasi salah satu kemampuan arsitektur tradisional yang mampu diadaptasi menjadi desain temporary shelter, yaitu kemampuan knock-down pada arsitektur suku Jawa, Joglo. Dengan demikian, penelitian mengenai adaptabilitas Joglo sebagai temporary shelter perlu dilakukan dengan tujuan: (1) mengetahui kelemahan dan potensi dari arsitektur Joglo jika digunakan dalam penerapan rancangan temporary shelter; dan (2) mengembangkan purwarupa desain dari temporary shelter yang mengadaptasi dan arsitektur Joglo.

Metode penelitian yang digunakan adalah metode riset terapan atau eksperimen, yang berfokus pada desain yang mengadaptasi arsitektur Joglo pada sistem bongkar pasang yang diaplikasikan pada temporary shelter. Data yang digunakan dalam penelitian adalah kriteria desain temporary shelter yang dikemukakan oleh UNHCR (2011) dan fungsionalitas dan keteknikan arsitektur Joglo yang dipaparkan oleh Frick (1997). Setelah mengetahui data mengenai arsitektur Joglo, maka data tersebut akan diuji terhadap kriteria desain temporary shelter dalam aspek efektivitas dan efisiensi. Tahap selanjutnya merupakan penentuan potensi dan kelemahan arsitektur Joglo sebagai temporary shelter.

Potensi-potensi akan dikembangkan lebih lanjut, sementara kelemahan-kelemahan arsitektur Joglo akan diatasi tanpa mengurangi potensi yang ada. Tahap selanjutnya adalah mengembangkan 2 tipe purwarupa desain temporary shelter dengan alternatif pada material konstruksi, dimana material kayu kelapa (tipe I) dan bambu wulung (tipe II) digunakan untuk menggantikan kayu jati, material otentik Joglo, yang dinilai kurang efisien. Kedua tipe ini, mampu memenuhi kriteria temporary shelter, karena cukup fungsional (efektif) dan memenuhi syarat keteknikan (efisien). Dengan penelitian ini, diharapkan kelak semakin banyak arsitektur tradisional yang diadaptasi dalam menangani isu aristektur pascabencana.

Kata Kunci: Joglo, knock-down, temporary shelter, pascagempa

\section{PENDAHULUAN}

Berdasarkan data yang diperoleh dari Badan Metereologi, Keikliman dan Geofisika atau BMKG, pada dasarnya, di Indonesia hampir setiap hari terjadi gempa bumi. Pulau Jawa, sebagai pulau di Indonesia yang paling rawan terkena gempa. Hal ini dikarenakan Pulau Jawa merupakan pulau dengan jumlah gunung berapi aktif terbanyak, yaitu 45 gunung berapi. Proses penyelamatan korban bencana gempa di Pulau Jawa juga memiliki tingkat kesulitan tinggi, karena jumlah populasi penghuni Pulau Jawa yang tinggi, yaitu kurang lebih 160 juta jiwa. Maka dari itu, muncul pemikiran atau gagasan mengenai lingkungan binaan yang tanggap dan adaptif terhadap bencana, guna memenuhi kebutuhan akan fisik-spasial pada korban bencana alam di Pulau Jawa. Salah satu gagasan ini telah terwujud dalam bentuk temporary shelter.

Berdasarkan Guidelines Design for Temporary Shelters After Earthquakes Based on Community Participation oleh Javan dkk. (2008), berbeda dengan emergency shelter dan permanent shelter, temporary shelter merupakan shelter yang tidak permanen dan tidak harus memenuhi seluruh kriteria dari permanent shelter, namun di sisi lain temporary shelter juga harus memenuhi kebutuhan hidup minimum penggunanya selama 1-2 tahun. Dengan demikian, dibutuhkan kriteria spesifik dalam perancangan konsep-konsep dasar temporary shelter. Dikarenakan sifatnya yang temporer, metode konstruksi dan perancangan shelter ini harus dirancang secara efektif dan efisien.

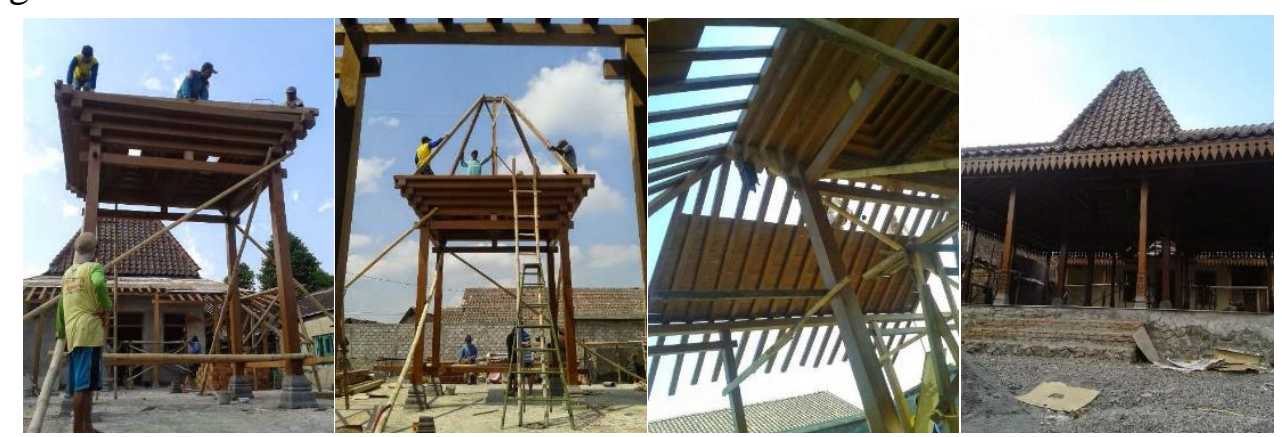

Figur 1. Proses Pembangunan Joglo 
Berdasarkan kriteria-kriteria yang dikemukakan oleh United Nations High Comissioner for Refugees atau UNHCR (2011) dalam buku yang berjudul Humanitarian Charter and Minimum Standards in Humanitarian Response, temporary shelter harus fit to user dan fit to site. Dikarenakan waktu penggunaan yang tergolong lama meski hanya bersifat temporer. Maka dari itu, arsitektur lokal Jawa, Joglo merupakan jawaban dari tuntutan kriteria tersebut, karena merupakan desain bangunan yang mampu merespon konteksnya, yaitu Pulau Jawa dan memang diperuntukkan untuk mengakomodasi adat dan budaya masyarakatnya. Namun, diperoleh dugaan sementara bahwa material utamanya, yaitu kayu jati, tidak mampu menjawab tuntutan keefektifan dari temporary shelter, dikarenakan langkanya material, beban material yang berat dan harganya yang mahal. Adapun tujuan dari penelitian mengenai adaptasi arsitektur Joglo pada temporary shelter adalah sebagai berikut.

- Mengetahui kelemahan dan potensi dari arsitektur Joglo jika digunakan dalam penerapan rancangan temporary shelter

- Mengembangkan purwarupa desain dari temporary shelter yang mengadaptasi dan arsitektur Joglo

\section{KAJIAN TEORI}

Apabila menelaah arsitektur tradisional, arsitektur lokal suku Jawa, yakni Joglo merupakan bangunan yang memiliki kemampuan untuk di bongkar-pasang (knock-down). Menurut Frick (1997), dalam bukunya yang berjudul Pola Struktural dan Teknik Bangunan di Indonesia, desain sambungan bangunan Joglo terinspirasi dari filosofi bahwa dalam membendakan segala sesuatu harus dimetaforakan dari karakteristik pembendanya, yakni manusia. Manusia memiliki tempat, namun memiliki kemampuan untuk berpindah, demikian juga dengan bangunan Joglo, sehingga desain bangunan dan sistem sambungannya didesain sedemikian rupa.

\section{METODA PENELITIAN}

Metode penelitian yang digunakan adalah metode riset terapan atau eksperimen, yang berfokus pada desain yang mengadaptasi arsitektur Joglo pada sistem bongkar pasang yang diaplikasikan pada temporary shelter. Data yang digunakan dalam penelitian adalah kriteria desain temporary shelter yang dikemukakan oleh UNHCR (2011) dan fungsionalitas dan keteknikan arsitektur Joglo yang dipaparkan oleh Frick (1997). Setelah mengetahui data mengenai arsitektur Joglo, maka data tersebut akan diuji terhadap kriteria desain temporary shelter dalam aspek efektivitas dan efisiensi. Tahap selanjutnya merupakan penentuan potensi dan kelemahan arsitektur Joglo sebagai temporary shelter.

\section{ANALISA}

\subsection{ARSITEKTUR JOGLO YANG DIAPLIKASIKAN SEBAGAI TEMPORARY SHELTER}

Berdasarkan UNHCR (2011), temporary shelter mempunyai kriteria desain yang dapat dikelompokkan menjadi 2 aspek: efektivitas dan efisiensi.

Efektivitas: Mampu Mengakomodasi Kebutuhan Sehari-hari. Temporary shelter merupakan shelter yang berada dalam tahap transisi yang digunakan selayaknya rumah tinggal, namun hanya dalam jangka waktu 1-2 tahun atau lebih. Maka, untuk memenuhi aspek 
ergonomi dan fungsionalitas ruang, ada beberapa aspek yang harus terpenuhi dalam perancangan temporary shelter.

\section{- Memenuhi Standar Antropometri Ruang Minimal}

Dalam mengakomodasi kegiatan dan jumlah pengguna temporary shelter, ruanganruangan di dalamnya harus cukup memadai apabila ditinjau dari aspek antropometri per jumlah pengguna. Berdasarkan standar yang dikeluarkan oleh UNHCR, luas minimum yang harus disediakan adalah $3.5 \mathrm{~m}^{2}$ dengan elevasi floor to ceiling minimal 2 meter.

\section{- Pola Ruang Fleksibel}

Ruang-ruang yang fleksibel bertujuan untuk menyesuaikan dengan adat, kebiasaan, bahkan aktivitas tertentu pada masing-masing keluarga yang menempati temporary shelter, karena kebutuhan dan kebiasaan masing-masing keluarga dapat berbedabeda dan membutuhkan kriteria ruang yang berbeda pula.

\section{- Perlindungan terhadap Iklim}

Selain merespon pengguna, temporary shelter juga harus merespon iklim konteksnya, dalam kasus ini iklim tropis, agar pengguna mendapatkan keamanan dan kenyamanan maksimal

Efisiensi: Memenuhi Aspek Keteknikan. Selain ditinjau dari segi kebutuhan ruang, proses pembangunan dari temporary shelter juga harus memenuhi aspek-aspek tertentu agar temporary shelter dapat dibangun seefisien mungkin.

\section{- Sambungan Knock-down}

Pembangunan temporary shelter dapat dipermudah dan dipercepat apabila, konstruksi bangunan dirancang secara knock-down. Sehingga, eksekusi di lapangan hanya perlu menghubungkan sambungan knock-down dari modul-modul dari temporary shelter.

- Beban Ringan

Bangunan temporary shelter harus memiliki beban yang ringan, mengingat keterbatasan sumber daya manusia yang membangun, sementara ugensi dari temporary shelter sangat tinggi. Maka dari itu, beban material konstruksi yang ringan dapat mempercepat waktu pembangunan.

- Ketersediaan Material

Material konstruksi harus mudah didapapatkan dan memiliki biaya yang relatif murah, dikarenakan kerugian yang ditimbulkan dari gempa bumi sudah cukup besar, maka diperlukan penghematan biaya pada material serta kemudahan untuk mengaksesnya.

\section{- $\quad$ Struktur Kompak}

Kekompakan struktur menjadi aspek yang menentukan kemampuan temporary shelter untuk dipindah dan kecepatan pembangunannya. Semakin kompak, semakin mudah dipindah dan menghemat biaya transportasi.

\section{- Kemampuan Untuk Dikembangkan}

Temporary shelter memang didesain secara temporer, namun tidak menutup kemungkinan bahwa shelter ini dapat digunakan lebih lama atau bahkan dijadikan shelter permanen. Maka dari itu, penambahan luas dan jumlah pengguna menjadi pertimbangan agar temporary shelter memiliki kemampuan untuk dikembangkan.

\section{- Ketahanan terhadap Gempa}

Dalam lokasi pembangunan temporary shelter, tidak menutup kemungkinan untuk terjadi gempa susulan, maka temporary shelter harus memiliki ketahanan terhadap gempa yang cukup. 
Sementara itu arsitektur Joglo juga dapat ditinjau dari 2 aspek, yaknbi fungsionalitas ruang dan keteknikan proses pembangunan.

Fungsionalitas Arsitektur Joglo. Arsitektur Joglo pada umumnya digunakan sebagai fungsi rumah tinggal. Sehingga, fungsi awal bangunan tradisional ini memang dapat diaplikasikan pada temporary shelter.

\section{- Tatanan Arsitektur Joglo}

Tatanan arsitektur Joglo memiliki 3 bagian, yaitu bagian kepala, badan dan kaki sesuai analogi bagian tubuh manusia, dimana masing-masing zona memiliki tingkat keprivasian yang berbeda. Tatanan pada arsitektur Joglo terkait dengan arah mata angin, terutama pada sumbu Utara dan Selatan, dimana setiap rumah harus mengikuti sumbu ini. Sehingga perletakkannya tergolong kaku apabila terpatok dengan konsep otentiknya

Namun, tatanan ruang tengah atau pusat yang berdapat dipertahankan, karena ruang pusat ini memiliki potensi untuk mengembangkan ruang menjadi lebih luas. Ruang bagian tengah atau "dalem" merupakan ruang pusat yang menjadi inti atau core dari arsitektur Joglo. Ruang ini memiliki konfigurasi dasar yang mampu diperluas ke berbagai arah, sehingga bangunan dapat lebih fleksibel dalam menanggapi kebutuh an ruang penggunanya.

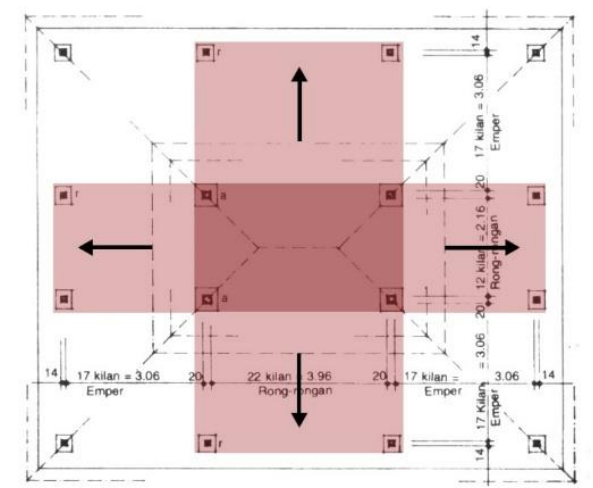

Figur 2. Potensi Pengembangan Ruang berdasarkan Saka Guru

\section{- Respon Terhadap Iklim pada Arsitektur Joglo}

Aplikasi filosofi bentuk berdasarkan budaya Jawa terhadap bangunan Joglo, tidak hanya digunakan simbol dan karakter semata, melainkan juga berperan dalam tropikalitasnya. Atap Joglo yang berbentuk menyerupai gunungan yang tinggi berperan dalam menghambat udara panas agar tidak langsung turun ke dalam ruang dalam. Atap yang dominan dengan teritisan yang lebar juga berperan dalam melindungi penghuninya dari sinar matahari berlebihan dan air hujan. Ruang semi terbuka atau teras berperan dalam melancarkan aliran udara dalam sistem cross ventilation yang diaplikasikan dalam bangunan Joglo

Dengan demikian, bangunan Joglo merupakan bangunan yang mampu melindungi penggunanya dari iklim tropis. Hal ini diakibatkan oleh penerapan makna-makna dan budaya Jawa pada bangunan, yang juga memiliki fungsi sebagai elemen-elemen pelindung penghuni dari iklim tropis. 


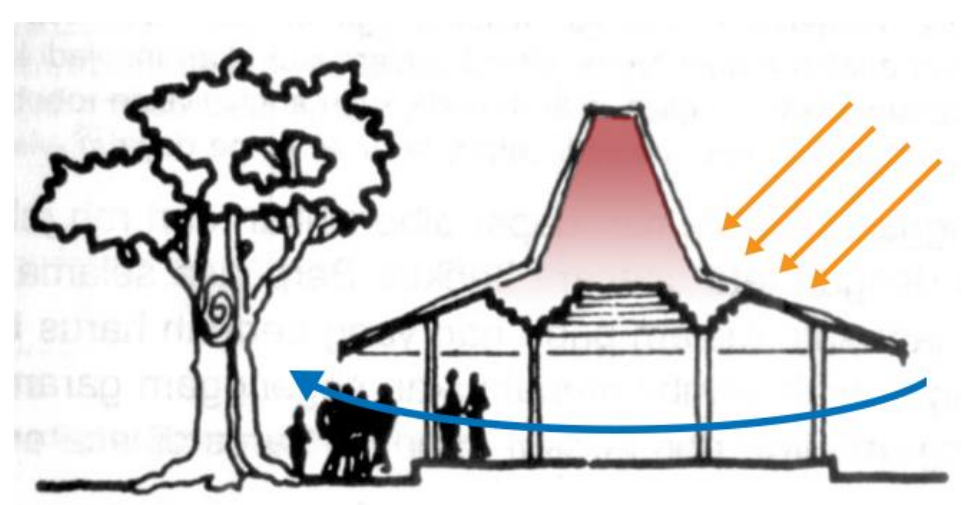

Figur 3. Ilustrasi Aplikasi Arsitektur Tropis pada Joglo

Keteknikan Arsitektur Joglo. Proses pembangunan merupakan aspek yang crucial apabila menyangkut temporary shelter, dikarenakan kebutuhan akan rumah tinggal pascagempa menjadi darurat sehingga harus efisien dalam berbagai aspek, terutama waktu dan biaya

\section{- Konstruksi dan Sistem Sambungan}

Konstruksi arsitektur Joglo memiliki kemampuan bongkar pasang yang menggunakan konstruksi kayu dan sistem sambungan bersifat sendi. Kemampuan knock-down dari bangunan Joglo juga berpengaruh pada kecepatan konstruksi dan pembongkarannya. Berdasarkan hasil wawancara dengan Bapak Toyib, selaku mandor tukang bangunan yang berdomisili di Jepara, Jawa Tengah, bangunan Joglo berukuran $20 \times 25 \mathrm{~m}^{2}$, dapat dibongkar dalam 1-2 hari dan dibangun kembali dalam waktu maksimal 30 hari dengan menggunakan tenaga manusia sebanyak 20 orang. Hal ini diduga dipengaruhi oleh elemen sambungan dan kontruksi kayu arsitektur Joglo yang memudahkan proses pembangunan dan pembongkaran di lapangan. Sambungan yang dimaksud adalah sambungan mortise tenon dan bibir lurus.
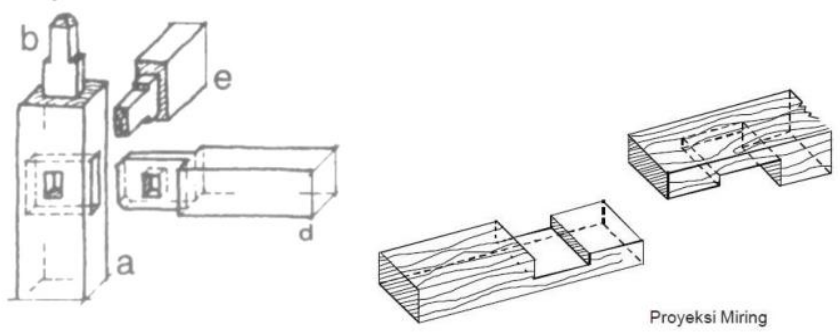

Figur 4. Sambungan Mortise-tenon dan Bibir Lurus

\section{- Struktur dan Pembebanan}

Berdasarkan konfigurasi kolom utama dan balok pada saka guru, dapat disimpulkan bahwa saka guru merupakan struktur inti utama bangunan Joglo. Penyaluran beban dilakukan secara gravitasional dan transversal, namun didominasi pada bagian saka guru. Sehingga, struktur inti pada bagian saka guru dapat dikembangkan lebih lanjut apabila di adaptasi pada bangunan modern. 


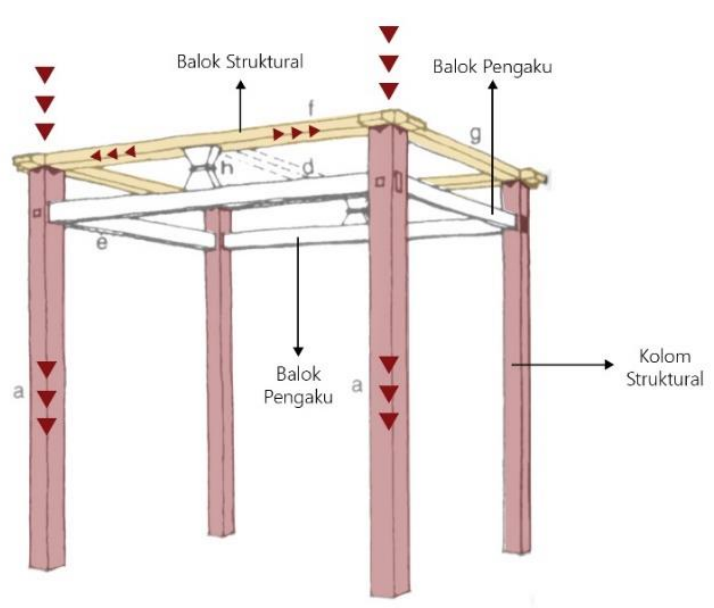

Figur 5. Penyaluran Beban pada Saka Guru

\section{- Material Struktural}

Material utama arsitektur Joglo berbahan dasar kayu jati, hal ini dikarenakan kemudahan untuk megakses material-material ini di sekitar Jawa. Material kayu jati sudah tergolong mahal pada zaman sekarang, sehingga hanya digunakan pada bangunan penting dan khusus untuk pembangunan saka guru saja.

Berdasarkan kriteria desain temporary shelter dan data tentang arsitektur Joglo, maka ditemukan beberapa potensi dan kelemahan arsitektur Joglo, apabila dialihfungsikan sebagai temporary shelter pascagempa dengan batasan wilayah di Pulau Jawa. Adapun potensi dari arsitektur Joglo sebagai temporary shelter antara lain sebagai berikut.

Potensi Arsitektur Joglo sebagai Temporary Shelter. Berdasarkan kriteria efektivitas temporary shelter, bangunan Joglo memiliki potensi antara lain sebagai berikut.

- Tatanan ruang (ruang dalem) bangunan Joglo memiliki kemampuan untuk dikembangkan (expandability) yang bersifat berulang dan modular dengan menggunakan standar antropometri UNHCR (2011)

- Arsitektur Joglo merupakan arsitektur yang mampu menanggapi iklim tropis, dengan demikian kemampuan bangunan dalam merespon terhadap iklim tropis dapat diaplikasikan dengan mengadaptasi bentuk dan proporsi atap bangunan, serta penggunaan material fasad yang tipis

Sementara itu, ditinjau dari kriteria efisiensi temporary shelter, konstruksi Joglo juga memiliki potensi antara lain sebagai berikut.

- Sistem dan atau sifat sambungan pasak kayu mortise tenon dan bibir lurus pada bagian saka guru dapat diadaptasi sebagai sambungan knock-down temporary shelter yang mempermudah workability dari bangunan ini.

- Konstruksi dan struktur inti bangunan (saka guru) dapat dikembangkan secara modular melalui modifikasi tertentu

- Dalam menanggapi gempa susulan, konfigurasi struktur dan sifat sambungan pada saka guru dapat diapatasi atau bahkan dipertahankan

Kelemahan Arsitektur Joglo sebagai Temporary Shelter. Berdasarkan hasil analisis dan kajian teori yang telah dibahas pada bab-bab sebelumnya, ditemukan kelemahan pada aspek efisiensi, yakni material bangunan Joglo. Kayu jati Jepara merupakan kayu yang sulit 
didapat dan tergolong mahal. Selain itu beban kayu jati juga berbanding dengan kekuatannya, sehingga kayu ini kurang praktis dan ringan apabila digunakan sebagai material temporary shelter.

\subsection{KONSEP DESAIN TEMPORARY SHELTER YANG MENGADAPTASI ARSITEKTUR JOGLO}

Dengan mengembangkan potensi dan mengatasi kelemahan dari arsitektur Joglo, maka dapat ditentukan konsep desain yang menjadi parameter desain purwarupa desain temporary shelter. Adapun konsep-konsep desain tersebut antara lain sebagai berikut.

Konsep Pengembangan Aspek Efektivitas. Potensi dari bangunan Joglo yang hendak dikembangkan sebagai temporary shelter perlu dikembangkan lebih lanjut, guna meningkatkan fungsionalitas dari temporary shelter.

\section{- Konsep Pengembangan Berdasarkan Standar Ruang Minimal}

Purwarupa desain dirancang untuk 4 orang dengan ukuran $3.5 \times 3.5 \mathrm{~m}^{2}$ yang menggunakan standar desain UNHCR (2011), yaitu $3.5 \mathrm{~m}^{2}$ per orang. Ukuran ini akan menjadi layout ruang modular yang memudahkan ekspansi bangunan ke 4 arah penjuru mata angin. Maka dari itu, dikembangkan pula unit-unit yang berukuran $3.5 \times 3.5 \mathrm{~m}^{2}$ dengan fungsi yang bervariasi, menyesuaikan dengan jumlah penghuni dan perkebangan program ruang.

Tabel 1. Unit-unit yang Dikembangkan Berdasarkan Kapasitas dan Program Ruang

\begin{tabular}{|c|c|c|}
\hline Ukuran Unit $\left(\mathbf{m}^{2}\right)$ & Kapasitas (orang) & Program Ruang \\
\hline $3.5 \times 3.5$ & $\begin{array}{l}\text { Keluarga Kecil } \\
\quad(4 \text { orang })\end{array}$ & $\begin{array}{l}\text { - Kamar Tidur } \\
\text { - } \quad \text { Area Kerja } \\
\text { Storage }\end{array}$ \\
\hline $3.5 \times 7$ & $\begin{array}{l}\text { Keluarga Kecil } \\
\quad(6 \text { orang) }\end{array}$ & $\begin{array}{ll}\text { - } & \text { Kamar Tidur (2) } \\
\text { - } & \text { Area Kerja } \\
\text { - } & \text { Storage }\end{array}$ \\
\hline $7 \times 7$ & $\begin{array}{l}\text { Keluarga Besar } \\
\quad(8 \text { orang) }\end{array}$ & $\begin{array}{ll}\text { - } & \text { Kamar Tidur (3) } \\
\text { - } & \text { Area Kerja } \\
\text { - } & \text { Storage } \\
\text { - } & \text { Teras }\end{array}$ \\
\hline $10.5 \times 10.5$ & $\begin{array}{l}\text { Ruang Komunal } \\
\text { (10 - 30 orang) }\end{array}$ & Menyesuaikan dengan fungsi \\
\hline
\end{tabular}

- Konsep Pengembangan Ruang Modular

Aspek tatanan ruang dan sistem struktur arsitektur Joglo pada dasarnya memiliki potensi yang dapat dikembangkan. Ditinjau dari tatanannya, arsitektur Joglo selalu memiliki pusat pada ruang "dalem" yang dapat dintreptasi sebagai bagian inti bangunan. Inti bangunan ini dapat diadaptasi kepada desain temporary shelter dan kelak diekspansi ke 4 arah penjuru mata angin. 


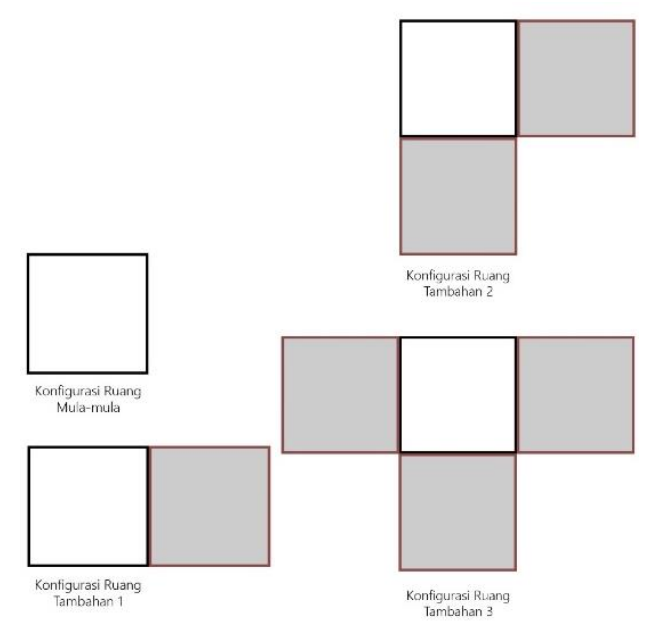

Figur 6. Ilustrasi Konsep Fleksibilitas Pengembangan Layout Ruang

\section{- Konsep Pengembangan Respon terhadap Iklim}

Elemen atap pada bangunan Joglo merupakan salah satu elemen bangunan yang paling merepresentasikan tropikalitas bangunannya. Ruang plafon yang tinggi dan teritisan yang lebar melindungi penghuninya dari transmisi termal berlebihan, sinar matahari langsung dan air hujan. Dengan demikian, tropikalitas yang akan diaplikasikan pada temporary shelter dapat berupa bentuk dan perbandingan proporsi atap Joglo itu sendiri.

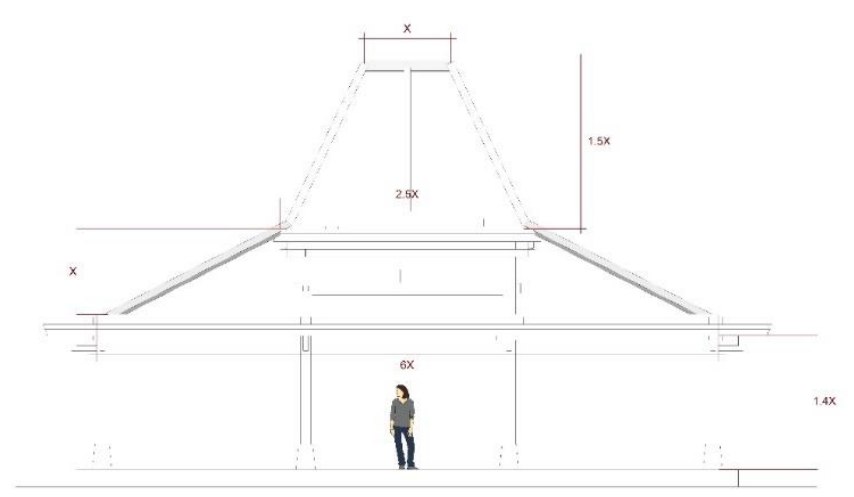

Figur 7. Perbandingan Proporsi pada Bangunan Joglo yang Dipertahankan

Konsep Pengembangan Aspek Efisiensi. Pada arsitektur Joglo terdapat beberapa potensi dan kelemahan dari bangunan Joglo apabila diadaptasi sebagai temporary shelter ditinjau dari segi efisiensi dan keteknikannya. Maka dari itu, diperlukan beberapa pengembangan dan modifikasi terhadap desain dan perencanaan konstruksi dari arsitektur Joglo, agar dapat memenuhi kemampuan standar temporary shelter dari aspek efisiensi dan keteknikan.

\section{- Penggunaan Bahan Bangunan Alternatif}

Kelemahan dari arsitektur Joglo apabila diterapkan sebagai temporary shelter merupakan material utamanya, yakni kayu jati. Kayu jati merupakan kayu yang sulit diperoleh, memiliki beban yang tergolong sangat berat dan harga yang mahal. Kelemahankelemahan ini menyebabkan proses konstruksi bangunan temporary shelter menjadi tidak 
efektif. Dengan demikian, diperlukan studi mengenai material pengganti kayu jati yang akan digunakan sebagai temporary shelter.

Dengan demikian terdapat beberapa material alternatif yang dapat digunakan untuk menggantikan material kayu Jati bangunan Joglo apabila diaplikasikan sebagai temporary shelter. Tujuan penggunaan 2 material alternatif adalah untuk mencegah terjadinya kelangkaan sumber daya salah satu material bangunan ketika dibutuhkan, sehingga material yang satu dapat menggantikan material lainnya apabila ketersediaan material sedang terbatas. Adapun 2 material yang mampu menggantikan kayu jati adalah kayu kelapa dan bambu wulung. Keduanya merupakan material yang terserbar luas di Pulau Jawa, murah dan mudah didapat.

\section{- Pengembangan Sistem Sambungan}

Apabila material yang digunakan dalam perancangan temporary shelter merupakan kayu yang menyerupai bentuk penampang kayu jati, maka sambungan-sambungan yang otentik pada bangunan Joglo dapat diaplikasikan kembali. Sambungan lokal akan lebih mudah dimengerti oleh warga lokal pula. Selain itu, sambungan lokal, yakni sambungan mortise-tenon dan bibir lurus, juga lebih mudah untuk dibuat oleh masyrakat, karena bentuk dan sistem sambungan ini sudah tidak asing lagi.

Apabila material tersedia memiliki bentuk penampang yang berbeda dengan kayu jati, bentuk sambungan asli, tidak dapat dipaksakan pada material tersebut. Namun, sifat sambungan, yaitu sambungan sendi dan kemampuan knock-down dari sambungan asli harus tetap dipertahankan, sehingga tidak mengubah prinsip-prinsp struktur dan konstruksi arsitektur Joglo.

\section{- Pengembangan Struktur Modular}

Tidak hanya ruangnya saja, melainkan kontruksi bagian ruang "dalem", yakni saka guru juga memiliki potensi untuk dikembangkan ke 4 arah penjuru mata angin. Namun, pengembangan saka guru pada Joglo hanya dapat dikembangkan ke 1 arah, maka dari itu, perlu modifikasi pada sistem struktur dan konstruksinya.

Modifikasi yang dimaksud dapat ditempuh melalui 2 pendekatan. Pendekatan yang pertama adalah mempertahankan sistem sambungan seperti sambungan mortise-tenon dan bibir lurus pada arsitektur Joglo, namun diperlukan modifikasi pada konfigurasi sambungan, sehingga balok pengaku dapat dikembangkan secara modular ke berbagai arah.

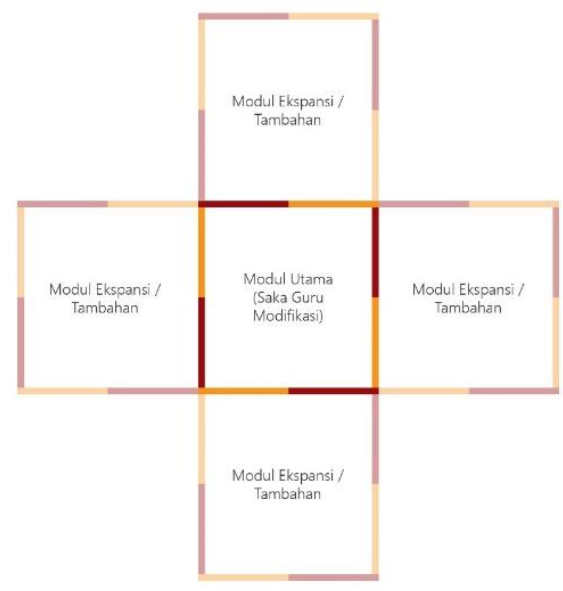

Figur 8. Ilustrasi Konsep Modularitas Struktur Saka Guru yang Dimodifikasi 
- Mempertahankan Prinsip Bangunan Tahan Gempa

Berdasarkan penelitian yang dilakukan oleh Prihatmaji (2007), bangunan Joglo sudah teruji kemampuannya dalam ketahanannya terhadap gempa. Maka dari itu, dalam merancang temporary shelter, diperlukan pula prinsip-prinsip ketahanan gempa. Adapun prinsipprinsip ketahanan gempa yang perlu dipertahankan antara lain

- Mempertahankan dan atau mengadaptasi sistem saka guru dan balok blandar pada bangunan Joglo

- Mempertahankan jenis sambungan sendi dan atau mempertahankan sistem sambungan pada bagian saka guru dan blandar

- Mempertahankan dan mengadaptasi prinsip balok brunjung sebagai penstabil struktur

- Mempertahankan sistem sambungan umpak dengan jenis sambungan sendi atau rol agar sifat elastis saat gempa tetap dipertahankan

\subsection{PENGEMBANGAN PURWARUPA DESAIN TIPE I}

Purwarupa desain temporary shelter tipe I merupakan desain yang menggunakan material konstruksi utama kayu kelapa atau kayu glugu. Hal ini dikarenakan kayu kelapa memiliki pasaran yang luas di Pulau Jawa dan Sulawesi, sehingga lebih mudah diperoleh ketimbang kayu jati. Sistem dan bentuk sambungan arsitektur Joglo juga dipertahankan, dikarenakan penampang struktur kayu kelapa yang serupa dengan kayu jati, sehingga mudah dikonstruksi oleh masyarakat lokal sekitar.

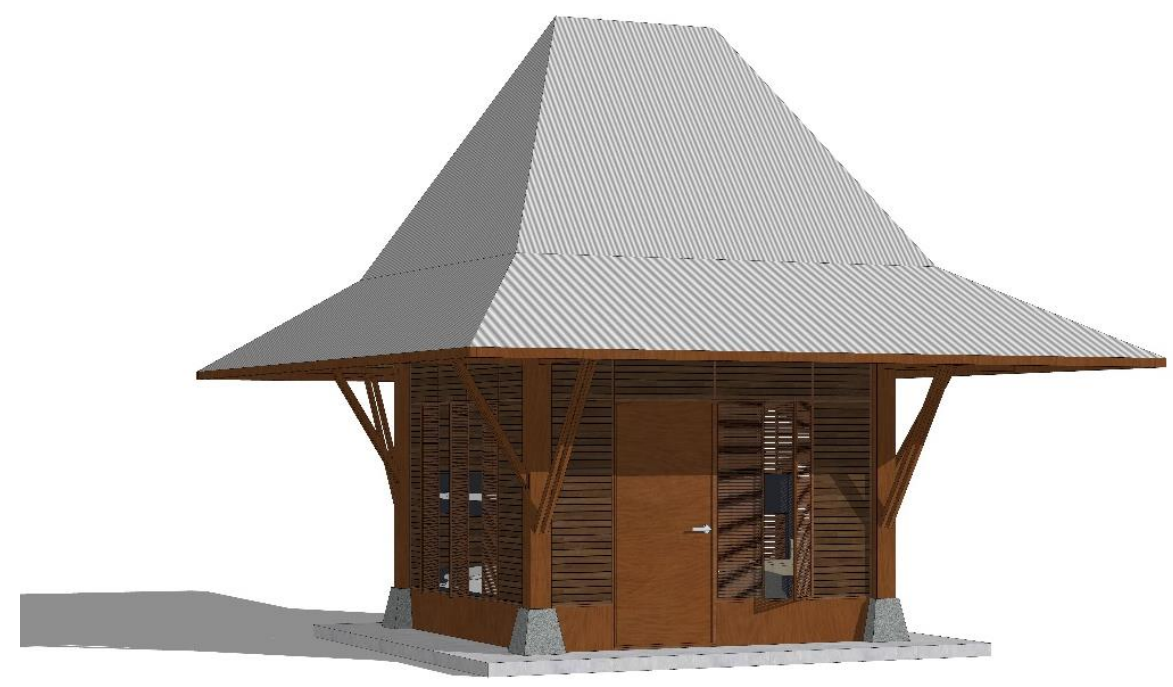

Figur 9. Purwarupa Desain Temporary Shelter Tipe I

Ukuran dari unit terkecil purwarupa tipe I adalah $3.5 \times 3.5 \mathrm{~m}^{2}$, sesuai dengan pedoman desain yang telah dipaparkan pada Bab V. Ruang dalam mampu mengakomodasi 4 orang dengan fungsi sebagai kamar tidur yang dilengkapi dengan storage dan area kerja.

Berdasarkan panduan desain yang dikemukakan oleh Javan (2008), unit sanitasi dan dapur terdapat pada bangunan umum yang terpisah. Hal ini dikarenakan zona utilitas pascagemnpa sulit untuk dikonstruksi dan relatif mahal, sehingga akan lebih efektif apabila untuk tahap awal, pemukiman pascagempa memiliki kamar mandi dan dapur yang bersifat komunal dan terpusat pada beberapa titik saja.

Guna menyesuaikan perkembangan program ruang dan jumlah pengguna yang bertambah di masa depan, maka ruang-ruang temporary shelter dirancang secara modular. 
Dengan ukuran standar $3.5 \times 3.5 \mathrm{~m}^{2}$ per unit, maka didapatkan beberapa alternatif pengembangan purwarupa tipe I dengan ukuran $3.5 \times 7 \mathrm{~m}^{2}$ dan $7 \times 7 \mathrm{~m}^{2}$.

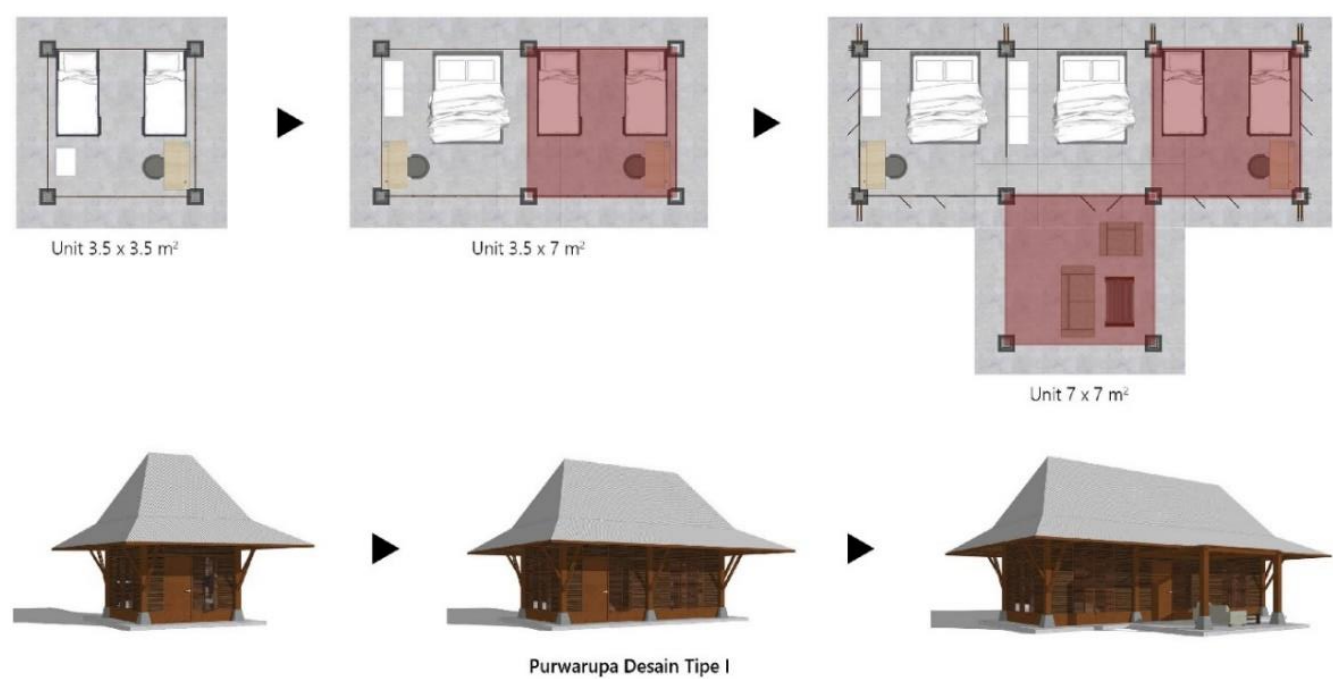

Figur 10. Pengembangan Ruang Purwarupa Desain Temporary Shelter Tipe I

Terdapat pula unit $10.5 \times 10.5 \mathrm{~m}^{2}$, dimana pengembangan untuk unit ini menyerupai bangunan Joglo yang asli. Tiang-tiang saka guru tidak dikembangkan pada unit ini, melainkan adanya penambahan tiang-tiang saka pengarak dan balok keliling seperti konstruksi arsitektur Joglo pada umumya.

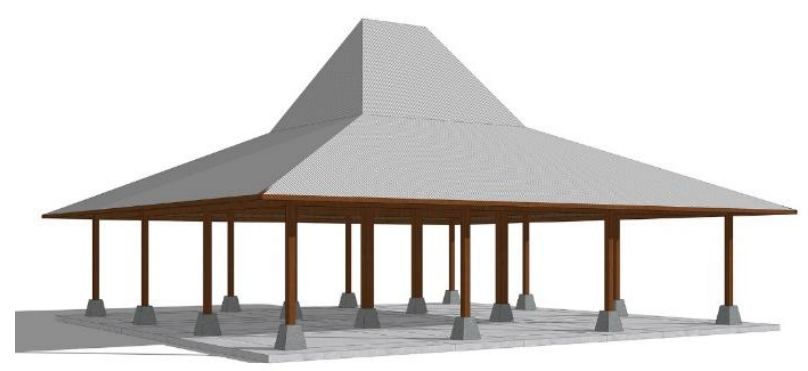

Figur 11. Pengembangan Unit dengan Ukuran $10.5 \times 10.5 \mathrm{~m}^{2}$

Ketropisan arsitektur Joglo dipresentasikan oleh elemen atap, dimana atap Joglo, selayaknya arsitektur tradisional Indonesia lainnya, mampu menghambat penyaluran radiasi panas, melindungi pengguna dari cahaya matahari berlebih dan air hujan. Dengan demikian, temporary shelter mempertahankan perbandingan proporsi atap arsitektur Joglo, guna mempertahankan prinsip-prinsip arsitektur tropis yang ada pada arsitektur Joglo.

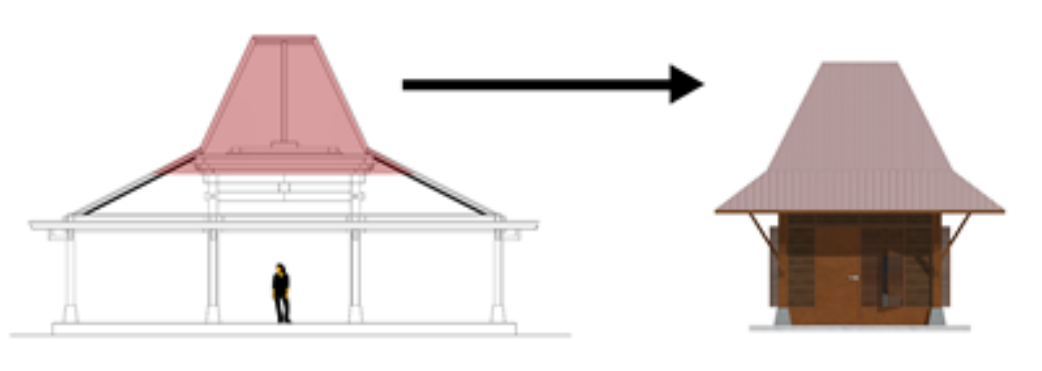


Mempertimbangkan pengembangan bangunan temporary shelter menjadi bangunan yang diperluas atau bahkan bangunan permanen, maka struktur bangunan juga harus mampu beradaptasi dengan pengembangan tersebut.

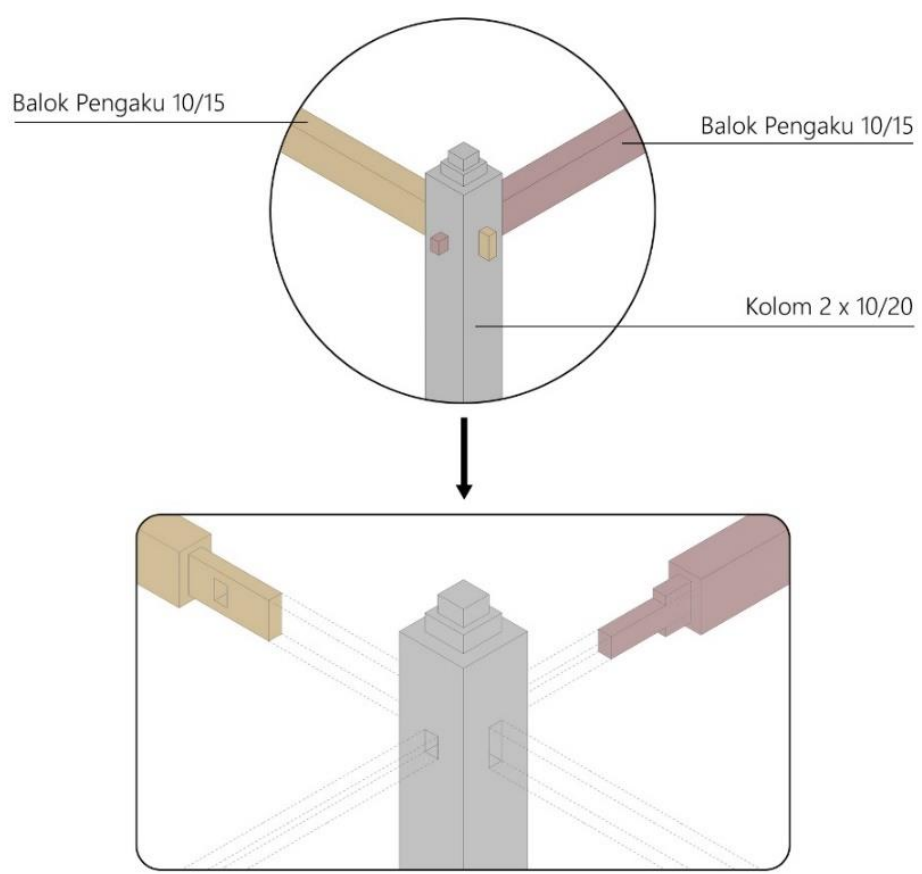

Figur 13. Detail Sambungan Mortise-tenon pada Saka Guru

Balok struktural yang digunakan pada temporary shelter tipe I memiliki tipe sambungan yang serupa pada tiap titik bangunan dan juga memiliki dimensi yang sama. Hal ini mengindikasikan bahwa secara penyaluran beban, struktur bangunan dapat dikembangkan dengan menggunakan konsep modularitas. Namun, berdasarkan figure 5 balok pengaku pada saka guru memiliki 2 tipe sambungan. Maka dari itu konfigurasi sambungan pada konstruksi saka guru perlu dimodifikasi ulang.

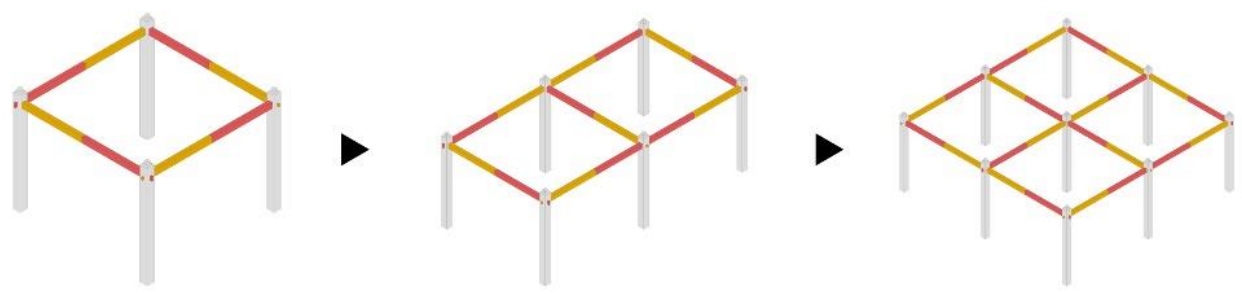

Figur 14. Modifikasi Pengembangan Temporary Shelter

Dikarenakan sistem sambungan yang identik dengan sambungan bangunan Joglo otentik, maka prinsip-prinsip ketahanan gempa di seluruh titik bangunan temporary shelter juga sama, yaitu bersifat sendi, dengan aplikasi sambungan berupa sambungan mortise tenon dan bibir lurus. 
Selain sistem sambungan, balok brunjung yang berlapis-lapis pada bangunan Joglo juga berperan dalam mempertahankan kestabilan bangunan. Namun, apabila diaplikasikan pada temporary shelter, dinilai tidak efisien dan membutuhkan waktu yang lama untuk konstruksi. Dengan demikian, kestabilan digantikan oleh elemen-elemen penstabil yang terletak pada balok pengaku.
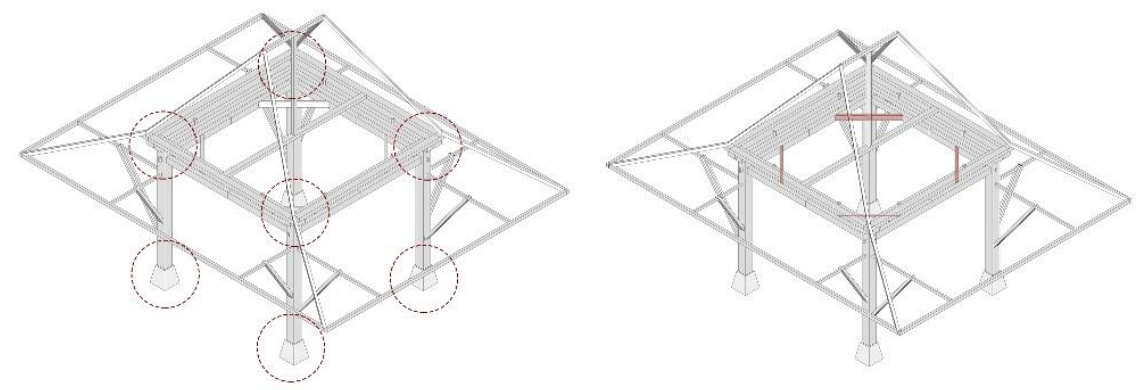

Figur 15. Aplikasi Sambungan Sendi (kiri) dan Pengaku (kanan) pada Tipe I

\subsection{PENGEMBANGAN PURWARUPA DESAIN TIPE II}

Purwarupa desain temporary shelter tipe II merupakan desain yang menggunakan material konstruksi utama bambu wulung. Hal ini dikarenakan bambu memiliki pasaran yang luas di Pulau Jawa, sehingga lebih mudah diperoleh ketimbang kayu jati, sekaligus mampu menjadi material alternatif apabila material kayu kelapa tidak sedang dalam masa produksi. Dikarenakan bentuk penampangnya yang berbeda, bentuk sambungan arsitektur Joglo harus direintepretasi ulang, namun sifat dan sistem sambungan dan struktur tetap berdasarkan pada dasar-dasar keteknikan arsitektur Joglo.

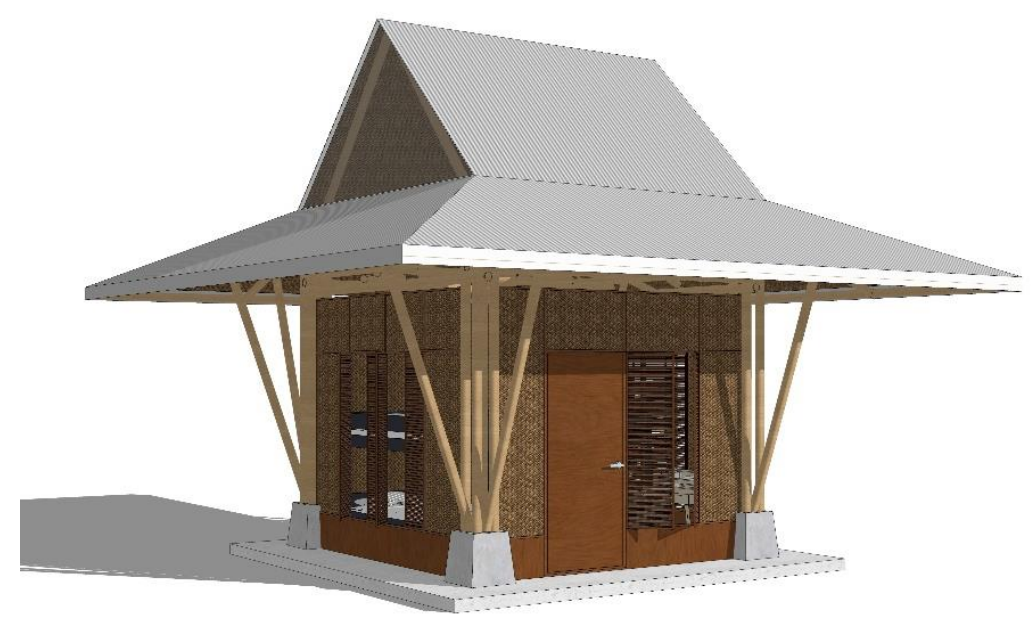

Figur 16. Purwarupa Desain Temporary Shelter Tipe II

Sama seperti temporary shelter tipe I, unit terkecil tipe purwarupa desain tipe II berukuran $3.5 \times 3.5 \mathrm{~m}^{2}$ yang diperuntukkan sebagai rumah tinggal sederhana untuk 4 orang. Unit terkecil ini dapat direplikasi dan dikembangkan luasannya menjadi unit $3.5 \times 7 \mathrm{~m}^{2}, 7 \times 7$ $\mathrm{m}^{2}$, dan $10.5 \times 10.5 \mathrm{~m}^{2}$. 


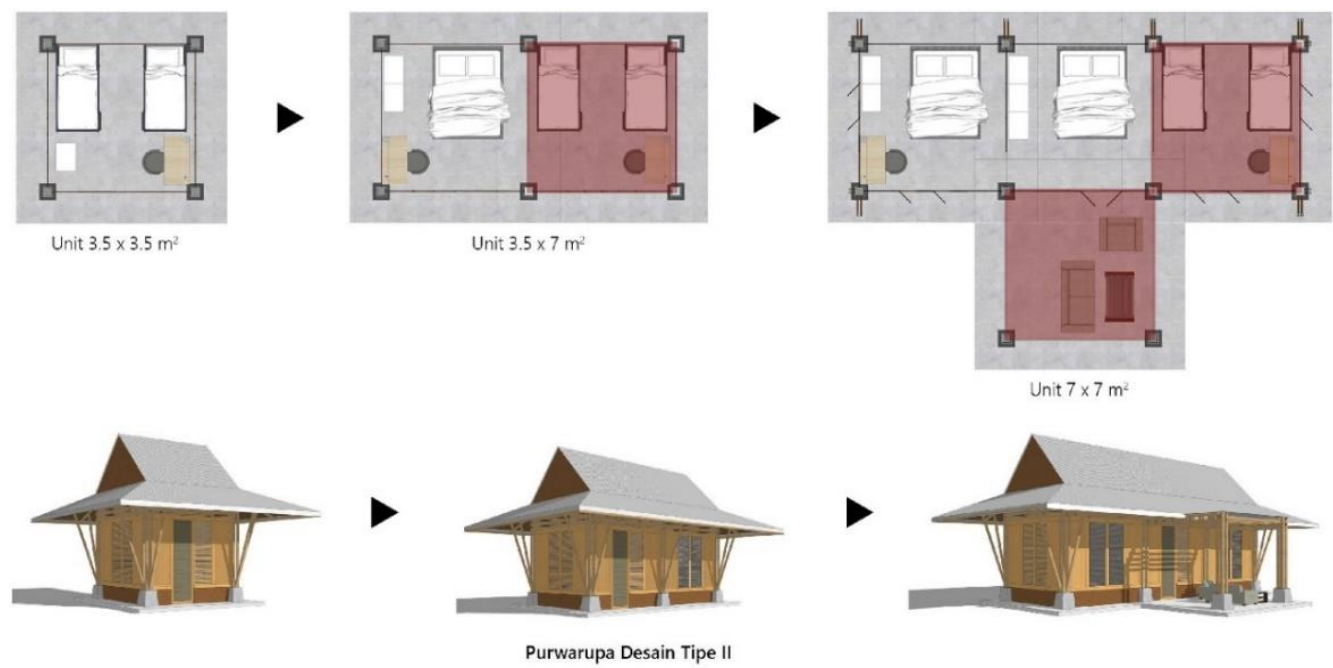

Figur 17. Pengembangan Ruang Purwarupa Desain Temporary Shelter Tipe II

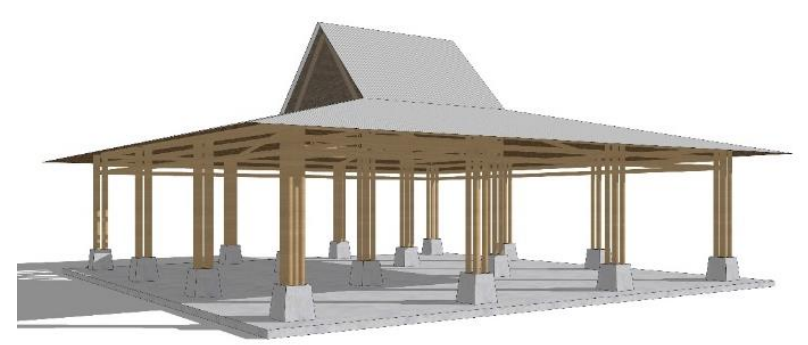

Figur 18. Pengembangan Unit dengan Ukuran 10.5 x $10.5 \mathrm{~m}^{2}$

Bentuk atap kedua temporary shelter juga mengadaptasi arsitektur Joglo sendiri, guna mencegah penyaluran udara panas yang berlebihan pada ruang dalam. Namun, dikarenakan perbedaan sistem sambungan pada material bangunan, temporary shelter tipe II mengadaptasi tipe bangunan Joglo jenis lainnya, namun tetap mempertahankan citra dan fungsionalitas atap Joglo.

Sementara pada temporary shelter tipe II, sambungan yang digunakan berbeda dengan sambungan kayu jati pada bangunan Joglo, namun sifat sambungan tetap dipertahankan, agar aspek knock-down temporary shelter pada arsitektur Joglo tetap berfungsi dengan baik.

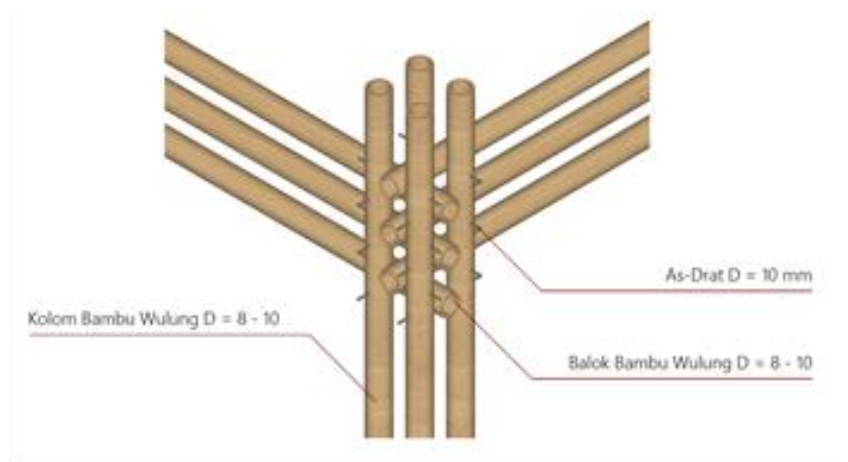

Figur 19. Contoh Sambungan Sendi Bambu Wulung pada Tipe II

Dikarenakan seluruh balok dikelompokkan menjadi 1 kategori, yakni balok struktural, maka temporary shelter tipe II dikembangkan dengan cara memperpanjang material struktural, 
yakni dengan menyambung balok bambu. Dengan demikian, perkembangan struktur secara modular dapat dilihat pada figur 20.

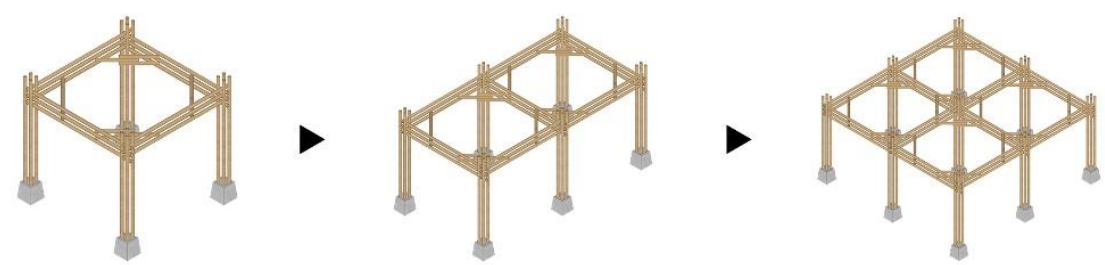

Figur 20. Modifikasi Pengembangan Temporary Shelter Tipe II

Dikarenakan mengadaptasi sistem sambungan bangunan Joglo otentik, maka prinsipprinsip ketahanan gempa di seluruh titik bangunan temporary shelter juga menyerupai, yaitu bersifat sendi, dengan aplikasi sambungan berupa sambungan pasak bambu.

Selain sistem sambungan, balok brunjung yang berlapis-lapis pada bangunan Joglo juga berperan dalam mempertahankan kestabilan bangunan. Namun, apabila diaplikasikan pada temporary shelter, dinilai tidak efisien dan membutuhkan waktu yang lama untuk konstruksi. Dengan demikian, kestabilan digantikan oleh elemen-elemen penstabil yang terletak pada balok pengaku.
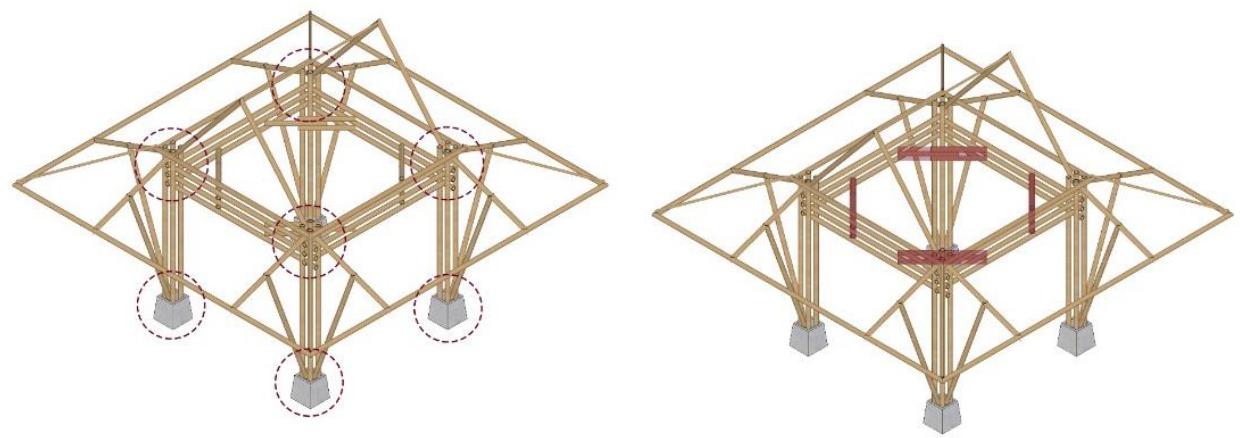

Figur 21. Aplikasi Sambungan Sendi (kiri) dan Pengaku (kanan) pada Tipe II

\section{KESIMPULAN}

Berdasarkan perbandingan terhadap temporary shelter tipe I dan II, dapat disimpulkan bahwa arsitektur Joglo dapat dikembangkan menjadi beberapa tipe purwarupa desain temporary shelter. Hal ini dikarenakan arsitektur Joglo memiliki potensi dalam aspek efektivitas (fungsionalitas) dan efisiensi (keteknikan) yang memenuhi kriteria temporary shelter berdasarkan standar yang dipaparkan UNHCR (2011). Meskipun menggunakan material dan tipe sambungan yang berbeda, kedua tipe purwarupa desain temporary shelter mampu mengakomodasi kebutuhan sehari-hari korban pascagempa, dan secara keteknikan cukup praktis dan memenuhi standar, sehingga tergolong cukup efisien.

Dengan adanya penelitian ini, diharapkan semakin banyak penelitian yang mengembangkan desain arsitektur resiliens yang terinspirasi dari arsitektur lokal. Adaptasi arsitektur lokal sebagai bangunan pascabencana, juga merupakan upaya dalam mempertahankan keberlangsungan arsitektur lokal, di tengah kemajuan zaman, karena 
arsitektur lokal dapat didirikan dalam berbagai keterbatasan, dimana kondisi tersebut serupa dengan kondisi pascabencana.

\section{DAFTAR PUSTAKA}

Badan Metereologi, Klimatologi dan Geofisika. Gempa Bumi Terkini (online). Tersedia di: http://www.bmkg.go.id/gempabumi/gempabumi-terkini.bmkg [diakses 4 Februari 2018]

Dunkelberg, Klaus, dkk. 1985. IL 31 Bambus - Bamboo. Stuttgart: University of Stuttgart

Frick, Heinz. 1997. Pola Struktural dan Teknik Bangunan di Indonesia. Yogyakarta: Kanisius.

Javan, Ali, dkk. 2008. Guidelines for Design of Temporary Shelters After Earthquakes Based On Community Participation. Beijing: The $14^{\text {th }}$ World Conference on Earthquake Engineering (WCEE).

Johar M., Deddy. 2013. Penerapan Material Kayu Kelapa pada Konstruksi Resort Pantai Goa Cina. Malang: Universitas Brawijaya.

K., R. Ismunandar. 1990. Joglo: Arsitektur Rumah Tradisional Jawa. Semarang: Dahara Prize

Maer, Bisatya W. 2008. Respon Pendopo Joglo Yogyakarta Terhadap Getaran Gempa Bumi. Surabaya: Universitas Kristen Petra

Meriam-Webster Online Dictionary [diakses 24 Januari 2018]

Prihatmaji, Yulianto P. 2007. Perilaku Rumah Tradisional Jawa "Joglo" Terhadap Gempa. Yogyakarta: Univeritas Islam Indonesia.

Remi. 2016. Kayu Pohon Kelapa sebagai Bahan Bangunan (online). Griya Mania. Tersedia di: https://griyamania.com/239/kayu-pohon-kelapa-sebagai-bahan-bangunan [diakses 11 April 2018]

United Nations High Commissioner for Refugees (UNHCR). 2011. Humanitarian Charter and Minimum Standards in Humanitarian Response. Bourton: The Sphere Project. 